\title{
NATURAM NATURANDUM
}

\section{Naturam Naturandum}

\author{
Lizardo Silva Guevara \\ Pontificia Universidad Católica del Perú \\ Lima - Perú \\ https://orcid.org/0000-0002-8572-0917 \\ Lisardo.silva@pucp.edu.pe
}

\begin{abstract}
RESUMEN
La identificación de Dios con la substancia en Spinoza viene desde su interpretación de la filosofía cartesiana al entender la substancia como necesaria en lugar de entenderla en su sentido esencialista. Así, hay una distinción escolástica entre la existencia substancial particularmente y la existencia de necesidad. Esta distinción sería la que Descartes alude en sus Principia philosophiae a propósito de su noción de substancia, y que Spinoza interpreta como equivalente. De este modo Spinoza identificaría la substancia, de característica esencial, con la característica de necesidad en el ser divino, dentro de su Etica ordine geométrico demonstrata. Como consecuencia él identifica a Dios con la substancia puesto que es realmente el único ser verdaderamente substancial que no hace sino congregar los distintos atributos expresados de distintos modos.
\end{abstract}

\section{Palabras clave:}

Dios, substancia, causalidad final, Descartes.

\begin{abstract}
The identification of God with substance on Spinoza's writings comes from his interpretation of cartesian philosophy, in as much as he understands substance as necessary instead of taking it in its essentialist sense. Thus, there's a scholastic distinction between substantial existence and necessary existence. This same distinction would be the one referred to in Descartes' Principia Philosophiae concerning his definition of substance; nevertheless, Spinoza interprets them as equivalent. In this way, Spinoza identifies substance, on its essentialist sense, with the feature of necessity of the divine being; all of this in his Etica ordine geometrico demonstrata. This results on the identification of God with substance, because he is indeed the only substantial being that gathers all the distinct attributes expressed in many modes.
\end{abstract}

\section{Keywords:}

God, substance, final causality, Descartes. 


\section{INTRODUCCIÓN}

Spinoza es sin lugar a dudas un autor muchas veces mal juzgado, fue juzgado duramente por la comunidad judía de Ámsterdam en su momento -la cual lo excomulgó de una manera muy bárbara-, fue malentendido por la autoridad católica española que obtuvo de oídas ${ }^{1}$ información sobre él y sus escritos, y en la historia de la filosofía ha sido catalogado como racionalista muy a pesar de que se desvincula de tal filosofía, si bien sí usa términos que son propiamente cartesianos para poder explicar a detalle sus propias posturas, además de usar una metodología silogística propia de la escolástica para su redacción sin ser él parte de esta corriente.

La posición teológica de Spinoza contrasta mucho con la escolástica cristiana, tradición de la que toma términos, pero redefiniéndolos para darles otro sentido y que le sirven como herramientas conceptuales para sus propios propósitos. Así, pues, tenemos conceptos tales como Dios, la substancia, finitud, y que influyen en otros como bien, mal, etc, además de que adquieren una connotación distinta en los escritos spinozianos. Solo basta recalcar que Dios para Spinoza no es el Dios de la escolástica cristiana ni de la comunidad judía de la cual fue expulsado, sino es la misma naturaleza (Deus sive Natura), cuyo ser no se agota solo en el mundo, sino que se expresa en éste y en sus individuos como distintos modos de esta divinidad. De ahí el nombre del presente artículo, Naturam naturandam, naturaleza que debe naturarse.
Así, en primer lugar, me gustaría contrastar la posición spinoziana de Dios con la de la tradición para que, a partir de ello, se entienda su relación con el mundo -que es el mismo Dios, de hecho -y con el hombre. Además, me gustaría desarrollar la implicancia de esta relación en vínculo con el aspecto epistemológico: qué o de qué modo se puede conocer a este Dios spinoziano. En segundo lugar, me gustaría justificar esta noción de Dios spinoziana recurriendo a precedentes filosóficos que hayan influido en Spinoza para tal creencia, sobre todo tomando la filosofía cartesiana como precedente directo de la filosofía spinoziana al menos desde su formulación de substancia.

\section{NOCIÓN DE DIOS}

Primero, hay que considerar la siguiente pregunta: ¿Qué se entiende por Dios?

En la tradición clásica aristotélica -de la que parte la escolástica precedente a Spinoza - se ha entendido a Dios como aquel Motor Inmóvil (akíneton²) que mueve todo lo demás. Este motor aristotélico, inmaterial, era considerado como Pensamiento del pensamiento, puesto que realiza la actividad más excelsa de todas, la cual es pensar, pero pensar al ser más excelso del cosmos, que resulta ser él mismo. Así, este dios es Pensamiento puro, y por ende, autointeligible. Ahora bien, aquello sirvió para brindar, en su momento, la ayuda de parte del concepto de Dios como postulado para resolver el problema del movimiento en el mundo sublunar y supralunar, sin identificarse nunca con este cosmos ni intervenir en los sucesos del mundo.

1 Es a propósito que uso esta expresión como asimilándola al primer género del conocimiento.

2 Hay que recordar que para el mundo griego, la kínesis -que se traduce al latín por motio y al castellano por movimiento -no representa solo el movimiento local, sino también la generación, la corrupción, el aumento y la disminución; es decir, todo tipo de cambio. Lo mismo aplica para su correspondiente en latín dentro de la filosofía medieval. 
Era solo un motor, y en ese sentido, un dios egoísta: no es un dios personal ni creador ${ }^{3}$.

Con la influencia del cristianismo, siglos más adelante, el Motor Inmóvil aristotélico pasaría a ser identificado con el Dios cristiano, pero personalizando a la divinidad, al punto que adquiere participación en los sucesos del mundo, por ejemplo, como causa eficiente de éste ${ }^{4}$. Así, por ejemplo, Tomás de Aquino expone -en la Summa Theologiae I, q. 2 a. 3 -las cinco vías para demostrar la existencia de Dios, y al concluir cada una de éstas, identifica a Dios con aquello que quiere demostrar que existe. Por ello, a la causa primera, al principio del movimiento, al ser necesario, a la máxima perfección, y a aquello que ha ordenado teleológicamente el mundo siendo él mismo su finalidad, a eso llamamos Dios, de acuerdo con él.

A aquello hay que agregarle que a Dios se le atribuye también la facultad volitiva. Cosa que no estaba en la concepción aristotélica original. Ahora que se reconoce la presencia de la voluntad divina, se entiende por qué Dios pasa también a ser creador o causa eficiente del mundo, así como decidir intervenir disponiendo de los seres creados.

Sin embargo, a esto hay que añadir un atributo importante que será crucial en Spinoza: la infinitud divina. Esta característica no proviene del Dios bíblico judeocristiano ni tampoco de la teología aristotélica, y posiblemente se remonte a Averroes en su teoría de la emanación y producción temporal, según Cortés (2015, 46). Curiosamente, ello se vislumbraría en la cuarta vía de Tomás de Aquino ${ }^{5}$ al proponer cuantitativamente los grados de ser hasta el sumo ser o la suma perfección. Pero recién vendría postulada tal cual como infinitud por el barroco Francisco Suárez, quien considerando que Dios posee todas las perfecciones en grado sumo, y comunicándole éstas a las criaturas, entonces pasa a considerarlo como el ser infinito. Sin embargo, según Suárez en Disputationes Metaphysicae XXVIII sec. 1, 18, infinito "no en la cantidad de masa sino en la excelencia de la perfección".

Con Descartes, proclamado padre del racionalismo, se da un viraje: el conocimiento de Dios no parte del presupuesto de la existencia de él hacia sus efectos, sino partiendo de lo que el hombre, el sujeto, en tanto que substancia que piensa, puede conocer, y partiendo de la idea del cogito puede recuperar a la res extensa y a la res infinita, Dios, como garante de las cosas del mundo y de la realidad objetiva como correlato de la realidad formal. Desde este autor racionalista, se vislumbra cómo se concibe la realidad, y que se diferencia

3 El mundo era entendido como eterno en la Antigüedad. No era concebido como algo con origen ex nihilo a partir de alguna causa eficiente divina, tal como sí lo concebiría el cristianismo siglos después.

4 Algo que para los griegos no era problema pues creían en la eternidad del mundo, no en un inicio de él. Así lo sostienen por ejemplo Parménides (quien sostiene que de la nada no se genera nada), Heráclito (quien considera que el cosmos no fue hecho por hombre o dioses, sino que ha sido, es, y será fuego viviente), Platón (que en el Timeo considera al Demiurgo eterno como el ordenador de la materia eterna), Aristóteles (quien sostiene que la materia no tiene ni principio ni fin en su existencia), según Marlasca (1985, p. 170) entre muchos, aunque no sea necesaria fuente alguna para tal conocimiento generalizado. En suma, los elementos de los que se compone el mundo material son eternos, no tienen ni principio ni fin.

5 La cuarta vía hace referencia a los grados de ser: las criaturas solo participan de un cierto grado de bondad, por ejemplo, y Dios es fuente de ella, es decir, es la bondad máxima. Y así con varias características, por lo que Dios es la suma perfección, o máxima perfección. 
de la precedente filosofía escolásticoaristotélica que consideraba un mundo multi substancial; Descartes considera solo tres rei-la res cogitans (el alma), la res extensa (el mundo), y la res infinita (Dios) -y si bien se dice que Dios es substancia, las otras dos lo serán por analogía con respecto a la divina. Esto último lo detallaré más adelante.

Además, la característica de infinitud propuesta originalmente por Suárez, Descartes la retomará también para orientar la explicación de la relación entre el ente finito y el ente infinito. ¿De qué manera? Pues primero hay que indicar que existe un paralelo entre el mundo y la razón, de tal manera que aquello que tenga mayor realidad formal, en la realidad extramental, tendrá mayor realidad objetiva, es decir en las ideas, teniendo éstas últimas su causa en la realidad formal. Así, el carácter cuantitativo de la gradualidad de participación del ente finito con respecto al ente infinito se vislumbrará a través de la idea de infinito que poseen los hombres en su mente, que solo puede existir como realidad objetiva en virtud de una realidad formal de lo infinito; pero a diferencia de la idea de finito que se origina en la percepción de la realidad formal de las cosas finitas, la idea de lo infinito al tener mayor estatus que la idea de lo finito entonces debe venir verdaderamente de una realidad formal correspondiente, y una cosa mientras más realidad tiene, más atributos tiene.

Por último, e influido por la filosofía anterior, Spinoza propondrá a Dios como ser infinito, esto es, como la substancia de infinitos atributos y cuya esencia es eterna e infinita (SPINOZA, Ética I, def. 6).
Así, en la medida en que Dios es infinito, la realidad no podrá ya entenderse de manera multi-sustancial, puesto que Dios no es substancia aparte de la naturaleza y que las cosas en el mundo -incluidos los seres humanos -son distintas expresiones de esta divinidad. Y aquellas cosas no podrían no estar incluidas en Dios, puesto que al ser infinito no puede carecer de alguna de sus partes, así como sin un atributo dejaría de ser Dios. Por tanto, Dios es la substancia y por ello está identificado con la naturaleza: Deus sive natura ${ }^{6}$.

Ahora bien, esta substancia de infinitos atributos que incluye todo lo existente en la medida en que es concebida por sí misma y en ese sentido es causa sui-tiene ella misma el principio de movimiento y de existencia por sî7. ¿De qué manera se expresa ello? Si bien no se puede afirmar que se exprese en otro, debido a que este Dios infinito involucra todo lo existente, entonces se debe concluir que este principio de existencia se expresa en acto en la Naturaleza, por ello ésta se identifica con Dios y sus infinitos atributos. Dios, entonces, pasa a ser la realidad natural misma cuya esencia se define como aquello sin lo cual la cosa no puede concebirse, entonces se concebirá como la potencia, pero también el acto de existir, al menos en el ser divino, el Deus sive Natura.

Por último, hay que considerar a dos probables influencias de Spinoza: Giordano Bruno, receptor de la filosofía neoplatónica, y Chasdai Crescas, como parte del misticismo judío. Si bien no se puede hablar de una influencia directa, son autores que Spinoza ha considerado,

6 Spinoza menciona que "...el ser eterno e infinito , al cual llamamos Dios o Naturaleza" (Ética IV, prefacio).

7 En la tradición aristotélica solamente se concebía que la physis poseía principio de movimiento por sí misma, mas no el principio de existencia por sí misma. 
e incluso al segundo lo nombra, y se les puede notar cierta inclinación a un monismo ambiguo.

El primero, Giordano Bruno, menciona algunas ideas que pueden sonar muy spinozianas pero con terminología distinta: primero que los seres humanos son considerados como accidentes de la substancia cósmica única, lo que se parece a la idea spinoziana de entes de la naturaleza como modos de la divinidad; segundo la idea de Dios como todo infinito que significa que excluye todo tipo de límite, lo cual es un viraje en la noción de infinitud divina; tercero y muy resaltante, la distinción entre natura naturans y natura naturata, siendo la primera Dios distinto de sus manifestaciones mientras que la segunda la automanifestación, lo que implica cierta inmanencia divina.

El segundo, Chasdai Crescas, consideraba que la materia preexiste en Dios, pues Dios es creador de todo y como aquello que es creado debe compartir la característica de quien lo crea, entonces la naturaleza, al ser material, revela que la materia preexiste también en la Divinidad. Solo así se explicaría que Dios pueda ser causa de la materia; y esto podría influir en la idea spinoziana de extensión como atributo divino.

Así, se entendería que Spinoza, siglos después, pero bajo la lectura de ambos autores, considere ideas tales como que Dios es inmanente al mundo y se muestra en sus distintas expresiones que finalmente pertenecen a la misma substancia divina; así como que considere la distinción conceptual, mas no ontológica, de naturaleza naturante y naturaleza naturada. Además, el Dios spinoziano, el Deus sive Natura, al ser inmanente al mundo y las cosas en él, pierde la característica de personalidad: no es un dios personal sino impersonal que solo se manifiesta y no conserva ni entendimiento ni voluntad (SPINOZA, Ética I, prop.17, escolio 2), o al menos no podrían llamarse entendimiento y voluntad en el sentido humano de los términos.

Pasaré a analizar, entonces, la proveniencia filosófica de la propuesta metafísica de Spinoza, que tiene como causa (y deviene en) una interpretación de la triple substancialidad cartesiana (mundo, alma y Dios) y cuyas consecuencias lógicas terminarán por transformar el dualismo del jesuita francés en un monismo metafísico y teológico.

Para entender qué causa la noción de Dios en Spinoza, hay que entender entonces su noción de substancia y analizar por qué la identifica con Dios; además también hay que considerar su postura sobre la des-teleologización del mundo para comprender por qué esta postura sobre la estructura del mundo influye en la postura sobre Dios, pues, como sabemos, Spinoza identifica el mundo (la naturaleza) con Dios. Empezaré, entonces, con el segundo tema (la crítica a la causalidad) que desestructura la visión teleológica del mundo, y concluiré luego con el primer tema, que atañe a su idea de substancia.

\section{PROBLEMA DE LA CAUSALIDAD:}

Primero, ¿de dónde parte la idea de que Dios se identifique con la naturaleza?

En este caso, tomaré como presupuesto el apéndice del Libro 1 de la Ética para poder deducir el porqué de la postura de Spinoza. La crítica ejercida en tal apéndice es la siguiente: existe un prejuicio teleológico, aquel que considera que todas las cosas del mundo están 
hechas con miras a una finalidad. De esta manera, los hombres creen que el mundo es un mero medio para un bien aún mayor, entonces no es él mismo una finalidad.

Así, se cree que el mundo, finito, contingente, causado, es creado por el ser infinito, necesario, incausado, etc, y además creado con un orden curiosamente antropocéntrico: el mundo es un medio para el bien del hombre. En segundo lugar, la finalidad última también implica un rendir culto a la deidad, lo que significa que las cosas del mundo serían hechos para (una aún mayor) perfección de Dios mismo ${ }^{8}$.

Esta visión teleológica del mundo descansa, de acuerdo con Spinoza, en que los hombres son ignorantes de las causas (puesto que no han llegado al tercer género del conocimiento ${ }^{9}$ ), por ende, al observar que las cosas manufacturadas por los mismos hombres tienen una funcionalidad como finalidad, de manera análoga llegan a creer que sucede con las cosas de la naturaleza y les atribuyen cierta finalidad: finalidad antropocentrista.

A esto habría que agregar el hecho de que los hombres, en su mayoría, están atrapados en el primer género del conocimiento -es decir, en la imaginación -que hace que conciban inadecuadamente al mundo, al no conocer sus causas. Entonces, no solo se tiene el problema de la ignorancia sino también de que la imaginación (del primer género del conocimiento) sea quien dirija la búsqueda de conocimiento.

Verdaderamente los hombres ignoran las causas ${ }^{10}$ pero tienen conciencia de sus apetitos y de sus voliciones, lo que provoca cierta creencia de libertad y además los lleva a actuar de acuerdo con sus apetitos, entendiendo la naturaleza como dotada para saciar estos apetitos; de donde viene la creencia - junto con la acción -teleológica. Es así como la ignorancia provoca la creencia tanto en la libertad como en el orden teleológico. A esto Spinoza lo llama como la "ficción humana", tal como se menciona en SPINOZA, Ética I, apéndice.

Así, por ejemplo, los hombres llaman bueno a todo lo que les es útil, y malo a lo contrario. Esto genera un conocimiento confuso no solo en el modelo del mundo -al asumirlo teleológico - sino también a nivel individual: la causa primaria de las acciones, el apetito, se ha confundido con causa final. Quienes tienen algún apetito que los mueve a actuar para satisfacerlo han pensado que la satisfacción de tal apetito es lo que dirige la acción, pero este apetito, por el contrario, es la causa primaria de la acción. Ello se muestra en la siguiente definición dada por nuestro autor neerlandés: "Por el fin a causa de lo cual hacemos algo, entiendo el apetito" (SPINOZA, Ética IV def. 7).

Además, Ramos-Alarcón complementa lo anterior con el siguiente ejemplo:

.sino sólo la imagen de beber agua. De ahí que el creyente en causas finales no sólo pensará que bebe el agua por su libre decisión, sino que la causa final del agua es rehidratar al cuerpo humano. Lo mismo sucede en otros casos: se dice que la alimentación humana es la causa final de las hierbas y los animales (2013, p.437).

8 Deducción a la cual llega Spinoza y que posteriormente criticará, pues al ser infinito no le falta nada, por definición.

9 A lo cual volveré posteriormente.

10 No se encuentran en el primer género del conocimiento, el conocimiento de la esencia. 
Así, lo bueno y lo malo no puede descansar sobre lo que place o displace a los sentidos humanos. De hecho, Spinoza adelanta que lo bueno y lo malo no existe tal cual, el mundo es neutral con respecto a ello, y solo se puede hablar de bien o mal dentro de una organización social ${ }^{11}$. ¿Por qué ya no se puede hablar de un bien y mal moralmente, sea en un sentido ontológico o en un sentido deontológico? Pues hay que recordar que la filosofía moral tiene una influencia grande de la escolástica aristotélica, y la palabra "bien" estaba asociada a la perfección ontológica del hombre, la cual era considerada como causa final en esta cosmovisión teleológica, la cual es negada por Spinoza. Así, el hombre encuentra como "bueno" a todo lo que le es útil para alcanzar su perfección, en este sentido, el bien está identificado con la utilidad. Sin embargo, la perfección ${ }^{12}$ en tanto que causal final, motor que justifica las acciones de los hombres, ya no es factible desde la nueva cosmovisión spinoziana; es más, el mundo ya no es un orden, menos uno teleológico, por tanto, el hombre tampoco puede tener una naturaleza finalista hacia un bien con vínculo en la trascendentalidad.

En consecuencia, lo anterior se refuerza con la siguiente mención hecha por Spinoza: "La perfección de las cosas debe estimarse por su sola naturaleza y potencia, y no (...) porque deleiten u ofendan los sentidos de los hombres (...) a la naturaleza humana" (Spinoza, Ética I, prop. 25). Caso contrario, al pensar lo bueno como causa final en relación con el bienestar del hombre, entonces eso además genera el peligro de provocar fluctuación del ánimo del hombre esperanzado o ilusionado con aquella causalidad, pues aquel hombre se aferra a aquella causa final a modo de ilusión y por desconocimiento de la causa eficiente, verdadera causa primaria.

Agrego a lo anterior, que, al no haber finalidad, el deseo de perseverancia solo se deseará por la misma perseverancia del ser, es decir, el conatus solo se buscará por sí mismo, no por un fin supremo, de acuerdo con la proposición 25 del libro IV: "Nadie se esfuerza en conservar su ser a causa de otra cosa" (Spinoza: Ética I, p. 25). Acordémonos que, para Spinoza, el conatus es la potencia de perseveración en el propio ser o de autopreservación, y en este sentido, pura actualidad formal del individuo como un todo ${ }^{13}$ que lo hace actuar en razón de su propia naturaleza (FALLAS, 2004, p. 28).

Si bien estas razones expuestas contra la teleología son abordadas desde una arista especulativa -en principio- también tienen una arista lógica, y es la siguiente: el mundo no puede estar teleológicamente ordenado por Dios puesto que siendo la máxima perfección ${ }^{14}$ no necesitaría añadirse nada más, sin embargo postular un mundo como medio para un fin mayor sería equivalente a decir que Dios no es su propia causa y finalidad sino que encuentra una perfección mayor en la finalidad para la cual está hecho el mundo, por lo que Dios no sería entonces perfecto. Por consiguiente, si Dios desea o apetece aquella finalidad, entonces desea

11 Si bien existe cierta perfección en el hombre en la medida en que aumente su conatus y se libere de las fluctuaciones del espíritu

12 Además, la idea de perfección clásica es diferente a la spinoziana que implica una consideración del conatus.

13 Y no solo como ego cogitans, como por ejemplo lo considera la tradición cartesiana.

14 De acuerdo con el prefacio del libro IV de la Ética, los hombres entienden perfecto en el sentido de acabado, de acuerdo con un molde o universal de aquello a lo que se refieren. 
esa perfección y en la medida en que solo se puede apetecer lo que se carece, Dios, por lo tanto, no es perfecto.

Por lo anteriormente señalado, queda constancia de que el mundo no solo no tiene un orden teleológico, sino que, en esa medida, los actos de los hombres tampoco responden a esta finalidad que justifica la instrumentalización de la naturaleza para bienestar antropocéntrico. Significa, también, que la relación de Dios con el mundo no es finalista, y que la perfección no es divina y no excluye a la inmanencia del mundo (RAMOSALARCÓN, 2013, p. 438).

\section{DIOS COMO LA SUSBTANCIA}

¿Por qué en la filosofía de Spinoza hay una identificación de Dios con la Substancia?

Para poder responder esta pregunta y comenzar a entender al Dios spinoziano, primero debe abordarse la noción de substancia. Spinoza define substancia como aquello que se concibe por sí y no por otro (SPINOZA, Ética I def. 3). Sin embargo, ¿de dónde sale esta idea de substancia que finalmente terminará identificando con Dios? Para esto hay que entender de donde viene este término.

Substantia es la palabra latina con que se traduce el término griego ousía de la filosofía aristotélica, que denota aquello de lo que se dice algo, es decir, el sujeto del predicado. Pues es "aquello que ni se dice del sujeto ni está en el sujeto v.g. el hombre individual o el caballo individual" (ARISTÓTELES, Categorías 2a11). De esta manera, se puede entender esta definición tanto como el sustrato que está detrás de los accidentes, es decir, la essentia, como también aquello que es en sí, la cosa concreta, bajo lo cual, substancia es aquello cuyas partes expresan determinación (CORTES, 2015, p.49). Cada cosa material en el mundo, desde este sentido, vendría a ser una substancia para la filosofía aristotélica, solo que cargando los accidentes (que no son substancia porque solo existen en otro y no por sí mismos), los cuales no la determinan pues sus propias partes determinan a la cosa. Y así, habría muchas substancias, es decir, habría muchas entidades.

Por otro lado, y siglos más adelante, tenemos a San Anselmo que da un giro importante en la noción de substancia al proponer que todas las cosas en el mundo tienen su ser desde una que les transfiere esta característica de existencia. Identifica, de esta manera, a la substancia, con la divinidad, pues es ella, en tanto que substancia que tiene su ser en sí misma, que le confiere ser a todas las demás cosas; así todas las cosas determinadas en el universo son llamadas substancia en virtud de su relación con aquella substancia primigenia, cuya existencia se identifica con ella misma, con su esencia. Además, sustancia divina es considerada como simple y, por consiguiente, acto puro -a diferencia de las substancias del mundo material -pues su simpleza hace que no dependa de un elemento externo que le brinde un principio unificador (como sucede, por ejemplo, con las cosas del mundo que son unión de materia y forma, o que pueden entenderse desde acto y potencia). Así, se extiende el concepto de substancia hacia la divinidad y se estrecha su vínculo entre ésta y los entes creados, entendiendo la substancialidad de los segundos como participativa en la substancialidad del primero.

En la misma línea de San Anselmo es que se situará San Buenaventura: la necesidad de distinguir entre una substancia increada que origine a otras substancias. Sin embargo, San Buenaventura no solo presentará la idea 
de finitud en las substancias creadas -lo que lleva a entender a Dios como causa eficiente de un mundo que no es eterno pero que tiene un comienzo en la creación -sino que hará la distinción de dos substancias participativas en el ser divino: la substancia corpórea y la substancia incorpórea.

Por último, Tomás de Aquino retoma tanto la filosofía aristotélica como también le tradición precedente y hace una última distinción importante para efectos del caso: la distinción entre substancia compuesta o material y substancia simple o inmaterial. Así, hay una jerarquía con respecto a ellas, pues la substancia primera, la simple, al ser forma pura no tiene accidentes; mientras que la substancia segunda, la compuesta, sí tiene accidentes y cambios. Esto derivará en que, siglos más tarde, el ente creado y el increado no puedan ser denominados como substancia de manera unívoca.

Hasta aquí, se ha entendido a la substancia como el sustrato lógico de lo predicado, en la antigüedad, lo que significa que cada cosa concreta lo es, pero se ha extendido esta substancialidad a la relación con su causa eficiente de donde toma su ser, es decir, la característica de substancialidad se extiende a Dios, desde San Anselmo. Y posteriormente se divide la substancia creada en corpórea e incorpórea; y se le añade una jerarquía que contrasta las características de la substancia primera con la segunda. Pero es esta última parte la más interesante: la substancia entendida desde Descartes y su influencia en la definición de tal término en Spinoza.

Nuestro autor neerlandés da la siguiente definición de substancia: "aquello que es en sí, y se concibe por sí, esto es, aquello cuyo concepto, para formarse, no precisa del concepto de otra cosa" (Spinoza: Ética I, def. 3). Esto tendrá como consecuencia que, desde la característica de infinitud en Dios, sea solo la divinidad a la que se le aplique tal denominativo, pues es lo único que puede explicarse sin acudir a una causa que lo genere, en la medida en que ella es causa sui, a diferencia de las cosas en el mundo, que son causadas.

Por otro lado, tenemos ahora al precedente racionalista de Spinoza en la historia de la filosofía, Descartes, que propone la siguiente noción de substancia en los Principia philosophiae: "Cuando concebimos la substancia solamente concebimos una cosa tal que existe en forma tal que no tiene necesidad sino de sí misma para existir" (DESCARTES, Principia Philosophiae I, 51).

Esto lleva como consecuencia lógica, aparentemente, que entonces sea solo Dios quien ostente ser substancia empero no lo pueden ostentar los entes creados por no ser autoexistente. El filósofo de La Fleche se anticipa a este problema planteado en el mismo parágrafo en el que da la definición de tal término y menciona que substancia no puede entenderse sino de manera análoga en Dios y en los entes creados ${ }^{15}$. Sumado a ello, también menciona que las cosas que dependen de otras para su existencia son llamadas atributos $^{16}$, mientras que aquellas cosas que solo dependen entonces de Dios serán llamadas substancias.

¿Por qué Descartes haría tal precisión de

15 Considerando la formación jesuita de Descartes, posiblemente se refiera al término suareciano de Analogía por atribución, pues los entes y Dios se entienden como substancias en la medida en que el ser de los entes les viene de Dios, y la substancialidad se entiende de diversos modos entre Dios y los entes. El otro tipo de atribución, por proporcionalidad, es aquel que mantiene un elemento metafórico.

16 Lo que, posteriormente en Spinoza, daría como resultado que los hombres no sean más que modos de estos atributos. 
substancia y la diferencia de los atributos si previamente había mencionado que substancia es solo análoga en Dios y en las criaturas? Pues bien, en la medida en que el filósofo francés desciende de una tradición escolástica, hay que entender su postura desde esa tradición. De acuerdo con Horrigan, aquella definición de substancia dada en los Principia Philosophiae como cosa existente que no necesita más que de sí misma para existir, es decir, como cosa autosubsistente, aludiría a que la substancia existe en sí misma (per se o autosubsistente ${ }^{17}$ ), mas no como accidente en otra cosa (per alio o existente en otra cosa); y no confunde aquello con lo que los escolásticos llaman ens a se, es decir, con el ente que existe necesariamente por sí mismo ${ }^{18}-\mathrm{y}$ que se diferencia del ens ab alio, el cual es el ente que tiene su existencia-contingente -desde otro y no por sí mismo (2018, p.4). La existencia y la esencia son lo mismo en Dios, pero en las criaturas difieren -sin que éstas pasen a tener una dependencia ontológica menor, como la accidental -y por ello Dios y los entes creados no pueden ser llamados propiamente "substancia" en un sentido unívoco sino análogo.

En este sentido, la definición de substancia cartesiana podría aplicar mutatis mutandi -análogamente a las cosas del mundo extenso, así también como al pensamiento en los hombres, en la medida en que son subsistentes no en el sentido de la innecesidad de una causa eficiente extrínseca para su existencia - como el caso de Dios o res infinita que es autoexistente -pues es patente que todas las demás cosas tienen un origen $a b$ alio; sino en la medida en que su ser no necesita, de manera intrínseca, apoyarse en alguna causa material o subjetivista para su subsistencia, como es el caso de los accidentes. Así, la substancia no es accidentalmente dependiente, como sí sucede con los accidentes con respecto a la substancia. Por ejemplo, el color es un accidente que no existe per se sino en una substancia que sí tiene existencia per se, mas no a se.

Es desde esta definición que se da pie al monismo spinoziano, pero ¿cómo así surge? Pues, Spinoza, influido por la definición cartesiana, sí identifica -O confunde -al ens a se (o autoexistencia) con la autosubsistencia per se, es decir, con la existencia de sí sin necesidad de causa extrínseca. Esto lleva a que la autosubsistencia (per se) y la necesidad (característica del ens a se) se identifiquen bajo la noción de substancia como si ambas fueran la misma característica.

Ahora bien, de acuerdo con Horrigan (2018, p.5), en Descartes ocurre otro problema que es difícilmente subsanable pero que ayudaría a entender el paso del dualismo cartesiano al monismo spinozista: la postulación de las dos substancias pasivas y la (in)justificación del vínculo entre ambas. Existe un dualismo antitético entre la esfera de la res cogitans, es decir, el pensamiento, y la esfera de la res extensa, es decir, la materia. Si esto es así, entonces, ¿de qué manera se vincularían ambas al estar en planos distintos o ser de distintas características? La respuesta de Descartes ante tal inconveniente es postular en el cerebro la glándula pineal, que se encargaría de conectar la recepción de actividades de conciencia -res cogitans- con la recepción de los movimientos mecánicos -res extensa -

17 Pero no autoexistente.

18 Ente que existe por necesidad, o que cuya existencia se identifica en su esencia. 
transformando lo percibido físicamente en espíritus animales que informan al alma de estas percepciones ${ }^{19}$. Así, se ha logrado convertir lo material en inmaterial, algo propio de la impresión sensible del cuerpo se transforma al lenguaje abstractivo que caracteriza al alma. Sin embargo, esto todavía descansa en el presupuesto de la concepción de la glándula pineal, lo cual podría sonar controvertido ${ }^{20}$.

Sin embargo, y volviendo a Spinoza, esta doble substancialidad cartesiana daría lugar a considerar que, en suma, estos dos ámbitos tienen su unión en la fuente de la cual toman su origen como causa eficiente, y ésta es Dios. Ello haría pensar que ambos -el pensamiento y la materia- son en realidad dos atributos de una misma substancia, y de paso identificando a Dios con ambos al ser la substancia infinita, la que pasa, por tanto, a ser inmanente a todos los fenómenos del mundo, pero dando diferentes expresiones de esta -ahora sí- autoexistente substancia, es decir, expresándose a sí mismo de distintos modos. Dando como resultado, de esta manera, al monismo de la metafísica de Spinoza (HORRIGAN, 2018, p.5). Tal vez, incluso, se le podría señalar como monismo de aspecto dualista si se obviara el hecho de que este doble aspecto en verdad corresponde a sólo dos de los infinitos atributos divinos.

La concepción de tal noción de substancia divina tiene como implicancia el hecho de que lo abarque todo, y ello excluye la posibilidad de una pluralidad de substancias. ¿De qué manera? Pues, de acuerdo con Spinoza, no puede haber más de una substancia, tal como clásicamente se ha pensado, pues éstas al tener el mismo atributo entonces pertenecerían a una misma naturaleza ${ }^{21}$, y no serían ellas propiamente hablando substancia sino modos o expresiones de una verdadera supra substancia (SPINOZA, Ética I, prop. 5). Y por si no fuera poco, la coherencia lógica de Spinoza nos imposibilita la producción de otra substancia en tiempo futuro, pues si sucediese eso significaría que aquella segunda substancia no es causa sui sino producida por otro, y aquello contradice la definición de tal término. En segundo lugar, también significaría que comparten algún atributo en común, $\mathrm{y}$ al tener un mismo atributo entonces nuevamente estaríamos situándonos no ante dos substancias sino ante dos modos o expresiones de la verdadera substancia (SPINOZA, Ética I, prop. 6 corolario). Y, agrego a ello el hecho de que la substancia ha sido concebida con infinitos atributos, así que solo por esa razón tampoco podría postularse una pluralidad de substancias ya que no serían más que partes de aquella infinitud; caso contrario, si no lo fueran, entonces la substancia no sería infinita, pero está probado que sí lo es²2.

Así, no solo es imposible la existencia de una pluralidad de substancias, en el sentido pre-spinoziano de la palabra, es decir, como una pluralidad de individuos en el mundo; sino que también sería imposible concebir más de una substancia en el sentido divino del término, es decir,

19 Los espíritus animales son un postulado cartesiano que pueden considerarse como un proto-modelo del sistema nervioso a futuro.

20 Aunque desde la posición cartesiana se podría afirmar que sin la existencia de tal glándula, o alguna cosa afín que conecte lo materia con lo inmaterial, entonces no habría conexión entre estos dos tipos de substancia, lo que se reflejaría en la incapacidad de abstraer las percepciones en ideas.

21 A una misma (y spinozistamente verdadera) substancia

22 Por modus tollens no podría haber pluralidad de substancias. 
dos o más Dioses o naturalezas son imposibles. Sin embargo, los antiguos y la tradición precedente han confundido a la substancia con sus modos, postulando así una pluralidad de substancias. Para poder explicar la razón de esto, hay que considerar la epistemología de Spinoza, es decir, los tres géneros del conocimiento propuestos por él: el primer género del conocimiento que consiste en la imaginación ${ }^{23}$, el segundo género del conocimiento, que consiste en el razonamiento ${ }^{24}$, y el tercer género que es el de la ciencia intuitiva ${ }^{25}$. Sólo los hombres que alcanzan un conocimiento de ciencia intuitiva -es decir, un conocimiento del tercer género -pueden conocer la naturaleza de la substancia. Sin embargo, el conocimiento difuso que causa esta confusión es producto de la imaginación, es decir, del primer género del conocimiento. Así pues, la imaginación, quien en su "libertad" 26 atribuye al concepto de substancia una característica inexistente, siendo ésta la pluralidad de substancias, y en ese sentido, confunde a la substancia con sus atributos y sus diversos modos.

Si bien en el Tratado sobre la reforma del entendimiento (Tractatus de intellectus enmendatione) distingue no tres sino cuatro modos de percepción (SPINOZA, Tractatus de Intellectus Emendatione, p. 26-29) -primero, la percepción por experiencia vaga; segundo, la percepción de oídas; tercero, la percepción por inferencia desde otra cosa; y cuarto, la percepción por la sola esencia de la cosa -finalmente quedarían los tres géneros del conocimiento aludidos en la Ética, los dos primeros de estos cuatro se pueden asimilar al primer género del conocimiento. Para efectos del caso, el conocimiento sobre la substancia divina debe ser óptimamente adquirido por la percepción de la esencia misma, esta es, aquello se logra por intuición, pues solo aquí se puede hablar de un conocimiento que no esté sujeto a error. Sin embargo, hay que recalcar que la demostración de la naturaleza divina, su necesidad substancial, Spinoza la ha esbozado desde el segundo género del conocimiento (CARAVEDO, 2016, p. 206207) que no tiene la misma intensidad que el conocimiento del tercer género pero que guarda un orden deductivo lógico que lo acerca a la infalibilidad, pero no llega a tener tal potencia e intensidad como el tercer género del conocimiento. Al menos eso parece indicar en el libro V:

"Pues, aunque en la Parte primera he mostrado, en general, que todas las cosas (y por consiguientemente, el alma humana) dependen de Dios tocante a la esencia y la existencia, con todo, aunque aquella demostración sea legítima y esté al abrigo de toda duda, no afecta a nuestra alma del mismo modo que cuando concluimos eso mismo a partir de la esencia misma de una cosa cualquiera singular, que decimos depende de Dios." (SPINOZA, Ética prop. 36 escolio).

Por último, y en concordancia con lo anterior, y a propósito del vínculo entre la divinidad y lo expresado a partir de ella, en el escolio de la proposición 29 del

23 La imaginación del primer género del conocimiento se produce por la afectación de los sentidos.

24 El razonamiento del segundo género del conocimiento se produce por inferencia a partir de otras cosas.

25 Con la scientia intuitiva (o también conocimiento intuitivo) en el tercer género se hace referencia al conocimiento intuitivo que forma una idea adecuada desde la sola esencia formal de la cosa.

26 Pongo entre comillas la palabra libertad pues solo se puede entender como libre a quien se haya liberado del estado de servidumbre por medio del conocimiento de causa adecuada. Ello implicaría al tercer género del conocimiento. 
libro I, Spinoza presentará una distinción importante, aunque conceptual, en la noción de Dios-Naturaleza: la distinción entre Natura naturans y natura naturata. La primera -natura naturans o naturaleza naturante -hace referencia a lo que es en sí, la potencia como causa inmanente de las cosas del mundo; mientras que la segunda -natura naturata o naturaleza naturada -corresponde, en contraste, a todo lo que se sigue de la necesidad de la naturaleza, como por ejemplo sus atributos. Esta doble conceptualización -que en realidad se refieren a la misma divinidad ontológicamente -proviene ya desde la filosofía de Giordano Bruno que tendría una inclinación monista -aunque no en sentido estricto $-y$ que influiría en Spinoza ${ }^{27}$. Recordemos que de ahí viene el el título de la presente obra: Naturam naturandum o Naturaleza que debe naturarse.

No es, entonces, un dualismo lo que presenta Spinoza en este escolio, sino una distinción conceptual de su sistema monista: Dios como naturaleza propiamente con la potencialidad infinita que lo caracteriza, y Dios en sus expresiones o modos, es decir, las cosas mismas o individuos de la naturaleza.

\section{CONCLUSIONES}

La metafísica spinoziana es novedosa pues contrasta con aquella de la tradición precedente (sea ésta la escolástica o la cartesiana, además de la cristiana y de la judía). Sin embargo, ella no puede entenderse aislada de estas tradiciones. Así, la idea de que Dios se identifica con la naturaleza viene ya desde la comprensión por parte del filósofo neerlandés de la noción de substancia dada por Descartes.
Esta definición de que substancia es todo lo que tiene solo necesidad de sí mismo para existir connota, para el autor francés, la característica de esencialidad, pero Spinoza al entender aquello desde la característica de necesidad deduce lógicamente que entonces solo Dios es substancia.

Así, independientemente de si la comprensión que Spinoza tiene de Descartes es adecuada o no, esto muestra la razón por la cual él identifica a Dios con la naturaleza como única substancia que explicaría la dualidad cartesiana desde una metafísica monista: una realidad monista que -en la filosofía cartesiana -tiene un aspecto dual, pero que no se reduce solamente a estos dos aspectos o atributos -siendo spinozistas -más bien siendo infinitos de los cuales solo conocemos estos dos (la extensión y el pensamiento) y que se manifiesta de distintos modos.

\section{REFERENCIAS BIBLIOGRÁFICAS}

Spinoza, B. (1980). Ética demostrada según el orden geométrico. Editorial Nacional.

Spinoza, B. (1988). Tratado de la reforma del entendimiento. Principios de la filosofía de Descartes. Pensamientos metafísicos. Alianza Editorial.

Caravedo, J. (2016) La ética de Spinoza: una terapia del amor mediante el conocimiento. Pucp.

Copleston, F. (1996). Historia de la Filosofía. Volumen IV. Editorial Ariel. Cortés, M. (2015). "Spinoza y la

27 Se sabe que de joven habría leído a Giordano Bruno. Posiblemente la terminología cartesiana le parecería más adecuada para racionalizar sus influencias filosóficas al generar su propia propuesta. 
herencia tardía en su pensamiento" en Saga: Revista de Estudiantes de. Filosofía. Volumen 16, Número 29. Bogotá, Universidad Nacional de Colombia. https://revistas.unal. edu.co/index.php/saga/article/ view/57027.

Descartes, René (2002). Los principios de la filosofía. Alianza Editorial.

Fallas, Fabrizzio (20014). El conatus como categoría radical en la teoría política de Spinoza. Revista de Filosofía de la Universidad de Costa Rica. 42 (106-107). Pp. 25-34.

Horrigan, Paul (2018). Critique of Descartes' definition of substance in Principles of Philosophy I, 51. (PDF) Critique of Descartes' Definition of Substance in 'Principles of \begin{tabular}{l|l} 
Philosophy,' I, 51 & Paul Gerard \\
\hline
\end{tabular} Horrigan - Academia.edu

Horrigan, Paul (2018). Critique on Spinoza of substance. (31) (PDF) Critique of Spinoza on Substance $\lfloor$ Paul Gerard Horrigan - Academia. edu.

Koistinen, Olli (2010). Cambridge companion to Spinoza's Ethics. Cambridge University Press.
Legorreta, Daniel (2018). La noción de substancia en el pensamiento escolástico. Sincronía. 73. Universidad de Guadalajara. https: //www.redalyc.org/ jatsRepo/5138/513853876006/ html/index.html

Marlasca López, A. (1985) La eternidad del mundo: un capítulo de filosofía medieval. Revista de Filosofía de la Universidad de Costa Rica, 23 (58). Pp. 169 - 182. www.inif. ucr.ac.cr/recursos/docs/Revista de Filosofía UCR/Vol. XXIII/No. 58/La eternidad del mundo un mapitulo de filosofia medieval.pdf

Ramos-Alarcón, L. (2013). La teleología en el modelo del hombre libre en Spinoza: discusión con Platón. Benítez, Laura y Velázquez, Alejandra (ed.). Tras las huellas de Platón y el platonismo en la Filosofía Moderna. De su simiente griega a la ilustración (pp. 423-466). UNAM.

Rice, Lee C. (1977) Emotion and conatus in Spinoza. Revue internationale de philosophie, 31 (119/120).

Fecha de recepción: 21/04/2021

Fecha de aceptación: 01/06/2021 